\title{
Evaluation of hypofunctioning thyroid nodules with technetium-99m MIBI and ultrasonography
}

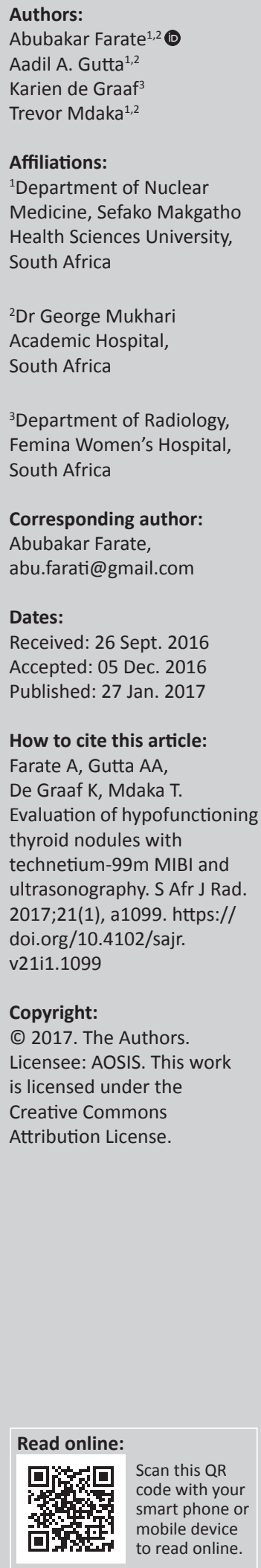

Background: Fine needle aspiration cytology (FNAC) cannot reliably differentiate follicular adenoma from follicular carcinoma (FC), which requires histological evidence of capsular or vascular invasion. FC is the most predominant thyroid cancer in our loco-regional environment, indicating the need for improvement in preoperative diagnostic accuracy of thyroid nodules to ensure appropriate and timely interventions.

Objective: The purpose of this study was to assess the role of technetium-99m methoxyisobutylisonitrile (99mTc-MIBI) scintigraphy and ultrasonography (USG) in the differential diagnosis of thyroid nodules.

Methods: Forty-two patients with hypofunctioning thyroid nodules were prospectively studied with 99mTc-MIBI scintigraphy and USG to differentiate benign from malignant nodules. An injection of $740 \mathrm{MBq}$ of $99 \mathrm{mTc}-\mathrm{MIBI}$ was intravenously administered, followed by semiquantitative analysis of dual-phase scans using a 4-point ( 0 to 3 ) scoring system. USG was subsequently performed and interpretation was based on some sonographic criteria for malignancy. In the following days and weeks, patients underwent FNAC followed by surgery and histopathologic examination.

Results: All malignant nodules were positive on 99mTc-MIBI and all but two malignant nodules were positive on USG. The sensitivity, specificity, positive predictive value (PPV), negative predictive value (NPV) and accuracy are, respectively, 100\%, 70\%,65\%, 100\%, and $81 \%$ for $99 \mathrm{mTc}-\mathrm{MIBI}$ scintigraphy; $87 \%, 78 \%, 68 \%, 91 \%$ and $81 \%$ for USG; and $83 \%, 100 \%, 100 \%, 96 \%$ and $64 \%$ for FNAC. There was no statistically significant difference between $99 \mathrm{mTc}-\mathrm{MIBI}$ scintigraphy and USG performance for both benign $(p=0.317)$ and malignant $(p=0.573)$ nodules.

Conclusion: 99mTc-MIBI scintigraphy and USG are important imaging modalities in the evaluation of thyroid nodules, particularly follicular neoplasms which are frequently associated with non-diagnostic cytology.

\section{Introduction}

Thyroid nodules are common clinical problems in the adult population with estimated prevalence of $2 \%$ to $6 \%$ by palpation and $19 \%$ to $35 \%$ by ultrasonographic technique. ${ }^{1}$ The majority of these nodules are benign with malignancy accounting for $5 \%$ or less. ${ }^{2}$ Early detection of differentiated thyroid carcinoma results in improved survival rate if completely excised and followed with radioiodine ablation.

Despite the generally good accuracy of fine needle aspiration cytology (FNAC), differentiating between benign and malignant follicular neoplasms remains challenging. This is particularly problematic in our loco-regional setting where follicular carcinoma (FC) is the most common form of primary thyroid cancer. ${ }^{3}$ A reliable diagnosis of FC can only be made when capsular or vascular invasion is seen on histologic examination. ${ }^{4}$ Deciding between total thyroidectomy and risky twostage surgery for malignancy found at postoperative histology is almost always a problem especially when the facility for frozen section is not available.

Functional thyroid imaging has been used for the evaluation of thyroid nodules, and a number of single photon emission computed tomography radiopharmaceuticals have been investigated. Technetium-99m methoxyisobutylisonitrile (99mTc-MIBI) has frequently been the tumourseeking agent of choice because of its availability, favourable radiation dosimetry and higher tumour-to-background ratios. ${ }^{5}$ Reports of other studies have shown that $99 \mathrm{mTc}-\mathrm{MIBI}$ scintigraphy is highly sensitive for thyroid neoplasia ${ }^{6,7,8}$ and has a high negative predictive value (NPV) for excluding malignant thyroid nodules. ${ }^{6,7,8,9,10}$ The studies of Mezosi et al., ${ }^{6}$ Hurtado-López et al., 
Wale et al. ${ }^{8}$ and Demirel et al. ${ }^{9}$ recorded sensitivity and NPV of $100 \%$ but they had very low specificity and positive predictive value (PPV). Although a negative 99mTc-MIBI scan virtually excludes malignancy in a hypofunctional thyroid nodule, the low specificity and PPV are problematic, thus necessitating the need for complementary diagnostic modalities such as ultrasonography (USG).

Ultrasonography is frequently the first-line imaging modality of choice for the evaluation of thyroid nodules because of its availability, non-invasiveness and lack of radiation exposure to the patient. It helps reveal clinically impalpable nodule(s) and can determine whether a nodule is solid or cystic, precisely define its size, site and number. USG has certain features that are suggestive of thyroid malignancy, including microcalcifications, marked hypoechogenicity, irregular or microlobulated margins, lesions assuming a taller than wider shape configuration, incomplete halo, marked intranodular vascularity pattern on colour or power Doppler, invasion of adjacent structures and presence of abnormal cervical lymphadenopathy. ${ }^{11}$ Smith-Bindman et al. ${ }^{12}$ identified intranodular microcalcifications as the strongest predictor of thyroid cancer. Studies have also shown that the likelihood of cancer in thyroid nodules increases with increasing number of sonographic characteristics of malignancy but at the expense of sensitivity. ${ }^{12,13}$ Cappelli et al. ${ }^{13}$ observed that ultrasound elastography is a very useful tool in the detection of malignancy in thyroid nodules when cytology results are inconclusive.

99mTc-MIBI scintigraphy and USG have been used independently in the evaluation of thyroid nodules. To the best of the authors' knowledge, literature reviews suggest that studies that assessed or compared USG (utilising both grey scale and Doppler sonographic criteria) and 99mTc-MIBI scan in the evaluation of hypofunctional thyroid nodules are limited. Erdem et al. ${ }^{14}$ evaluated thyroid nodules using 99mTc-tetrafosmin (a radiopharmaceutical similar to 99mTc-MIBI) scintigraphy and colour Doppler ultrasound. In their study, 99mTc-tetrafosmin was more sensitive compared with Doppler USG (sensitivity of $100 \%$ vs. $80 \%$ ). Demirel et al. ${ }^{9}$ compared the radionuclide thyroid angiography, 99mTc-MIBI and power Doppler ultrasound. They found power Doppler USG to be more sensitive than $99 \mathrm{mTc}-\mathrm{MIBI}$ scan (sensitivity of $100 \%$ vs. $67 \%$ ). The two studies, however, considered only the Doppler sonographic criteria.

The purpose of this study was to assess the diagnostic performances of $99 \mathrm{mTc}-\mathrm{MIBI}$ scintigraphy and USG in the preoperative evaluation of hypofunctional thyroid nodules, most importantly follicular thyroid neoplasms, and in addition, to compare the two imaging techniques.

\section{Methods}

\section{Subjects}

The study cohorts consisted of all eligible patients with thyroid nodule(s) who were referred for thyroid scintigraphy at the Nuclear Medicine Department, Dr George Mukhari Academic Hospital, Garankuwa between March 2013 and April 2014.
A nodule was defined as a palpable mass in the thyroid gland detected either by the patient or identified by a physician during neck examination. All patients had hypofunctional thyroid nodules as determined by $99 \mathrm{mTc}$-pertechnetate thyroid scintigraphy and all were euthyroid as confirmed by serum thyroid hormone measurements.

\section{Imaging protocol}

\section{Radionuclide imaging}

99mTc-pertechnetate scintigraphy: Twenty minutes after injection of $185 \mathrm{MBq}$ of $99 \mathrm{mTc}$-pertechnetate, anterior neck image was acquired with a large field-of-view gamma camera (E.CAM, Siemens Medical Solution USA, Inc., PA, USA) equipped with a low-energy, parallel-hole, high-resolution collimator. Acquisition was preset to 10 minutes (or 250000 counts) using a $256 \times 256$ matrix with a digital zoom of 2.0. The energy window was set at $20 \%$ and centred at the $140 \mathrm{keV}$ photopeak of $99 \mathrm{mTc}$. 99mTc-pertechnetate scan was performed to objectively determine the functionality of the nodule. Patients with hypofunctioning or cold nodule(s) were included in this study.

99mTc-MIBI scintigraphy: 99mTc-MIBI scan was performed within 3 to 7 days after the $99 \mathrm{mTc}$-pertecnnetate scan. Intravenous injection of $740 \mathrm{MBq}$ of $99 \mathrm{mTc}-\mathrm{MIBI}$ was followed by early ( 20 minutes) and delayed ( 2 hours) imaging of the thyroid under the same acquisition conditions as employed for the $99 \mathrm{mTc}$-pertechnetate scan. Each scan was evaluated by a fellowship-trained nuclear medicine physician with more than 5 years of experience who was blinded to the clinical data and ultrasound results. The $99 \mathrm{mTc}-\mathrm{MIBI}$ images were semiquantitatively analysed by a four-point scoring system ${ }^{10}$ : score-0: no significant uptake, score-1: uptake increased compared with the background activity but less than normal thyroid tissue, score-2: uptake equal to normal thyroid tissue and score-3: uptake greater than normal thyroid tissue with retention on the delayed image. We considered score- 3 to be positive for malignancy.

\section{Ultrasonography}

A board-certified radiologist performed USG with a Siemens Acuson X 300 scanner (Siemens Medical Solutions, CA, USA) using electronically focused near-field linear transducer with a bandwidth of 5-10 MHz. The radiologist had no prior knowledge of clinical data or scintigraphy. Malignant sonographic characteristics were defined as microcalcifications, type-3 intranodular vascularity (defined as intranodular flow with multiple vascular poles chaotically arranged, with or without significant perinodular vessels), a shape that was taller than it was wide, an irregular or microlobulated margin, marked hypoechogenicity and presence of an abnormal regional lymph node. We classified nodules as positive or negative. If a single feature suggestive of malignancy was present, the nodule was classified as positive. If a nodule had none of these features, it was classified as negative (benign). The results of 99mTc-MIBI scintigraphy and USG were compared with FNAC and histopathological findings. 


\section{Ultrasound-guided FNAC}

The same radiologist who performed the ultrasound examinations carried out the ultrasound-guided FNACs. The procedure was performed on all thyroid nodules with or without sonographic features suspicious of malignancy. Ultrasound-guided FNAC was performed with a 22-gauge needle attached to a 5-mL disposable plastic syringe. Each lesion was aspirated at least twice. The aspirated specimen was smeared on a glass slide and fixed in 95\% alcohol for Papanicolaou. Additional special staining was performed according to the requirements of the cytopathologists. Cytologic diagnoses were rendered by an experienced pathologist as benign, follicular neoplasm, indeterminate, inconclusive or malignant.

\section{Statistical analysis}

Statistical analysis was performed using Statistical Analysis System, Release 9.2, running under Microsoft Windows. Descriptive statistics such as mean, standard deviation, frequency and percentage were obtained.

The sensitivity, specificity, PPV, NPV and accuracy of each diagnostic method were calculated using two-by-two contingency tables based on the definitive histopathologic diagnosis.

The differences between the two modalities were assessed applying the Exact McNemar test. A $p<0.05$ was considered statistically significant.

\section{Results}

A total of 42 patients (39 women and 3 men) with hypofunctional thyroid nodule(s) were prospectively evaluated with $99 \mathrm{mTc}-\mathrm{MIBI}$ and USG. They were aged between 19 and 73 (mean age: $44.8 \pm 13.49$ ).

The nodules were classified according to histologic findings (Table 1). Of the 42 cases studied, 15 (35.7\%) were malignant and $27(64.3 \%)$ were benign at histology. The data confirmed the presence of FC in 8 of 15 nodules (53.3\%) and papillary carcinoma (PC) in 7 of 15 nodules (46.7\%). The benign cases comprised 17 colloid goitres, 6 nodular goitres, 2 follicular adenomas and 2 Hürthle cell adenomas.

99mTc-MIBI was positive in all the $15(100 \%)$ patients with carcinomas, whereas USG was positive in 13 of $15(86.7 \%)$ cases. False-positive findings were seen in 8 of $27(29.6 \%)$ patients on 99mTc-MIBI scintigraphy and in 6 of $27(22.2 \%)$ patients on USG.

There was no statistically significant difference between 99mTc-MIBI scintigraphy and USG performance for both benign $(p=0.317)$ and malignant $(p=0.573)$ nodules. When the two modalities were compared, $99 \mathrm{mTc}-\mathrm{MIBI}$ scintigraphy was more sensitive and had higher NPV than USG. However, USG was slightly more specific with marginally higher PPV than 99mTc-MIBI. Review of FNAC results showed that only 5 of $15(33 \%)$ histologically proven cancers had positive
TABLE 1: Summary of $99 \mathrm{mTc}-\mathrm{MIBI}$, ultrasonography and fine needle aspiration cytology findings in the assessment of thyroid nodules.

\begin{tabular}{|c|c|c|c|c|c|c|c|c|c|}
\hline \multirow{2}{*}{ Histology } & \multirow[t]{2}{*}{$n$} & \multicolumn{2}{|c|}{ 99mTc-MIBI } & \multicolumn{2}{|c|}{ USG } & \multicolumn{4}{|c|}{ FNAC } \\
\hline & & Pos. & Neg. & Pos. & Neg. & Ben. & Mal. & $\mathrm{FN}$ & Inc. \\
\hline Follicular $\mathrm{Ca}$ & 8 & 8 & 0 & 7 & 1 & 1 & 1 & 5 & 1 \\
\hline Papillary Ca & 7 & 7 & 0 & 6 & 1 & 0 & 4 & 1 & 2 \\
\hline $\begin{array}{l}\text { Follicular } \\
\text { adenoma }\end{array}$ & 2 & 2 & 0 & 0 & 2 & 0 & 0 & 2 & 0 \\
\hline $\begin{array}{l}\text { Hürthle cell } \\
\text { adenoma }\end{array}$ & 2 & 2 & 0 & 2 & 0 & 2 & 0 & 0 & 0 \\
\hline Colloid goitre & 17 & 2 & 15 & 1 & 16 & 16 & 0 & 1 & 0 \\
\hline $\begin{array}{l}\text { Nodular } \\
\text { goitre }\end{array}$ & 6 & 2 & 4 & 3 & 3 & 4 & 0 & 2 & 0 \\
\hline Total & 42 & 23 & 19 & 19 & 23 & 23 & 5 & 11 & 3 \\
\hline
\end{tabular}

USG, ultrasonography; FNAC, fine needle aspiration cytology; Pos., positive for malignancy; Neg., negative for malignancy; Ben., benign; Mal., malignant; FN, follicular neoplasm; Inc., inconclusive; Ca., carcinoma.

TABLE 2: Comparison of the diagnostic performances of $99 \mathrm{mTC}-\mathrm{MIBI}$, ultrasonography and fine needle aspiration cytology in the evaluation of thyroid nodules.

\begin{tabular}{lccc}
\hline Diagnostic test & 99mTc-MIBI & USG & FNAC \\
\hline Sensitivity (\%) & 100 & 87 & 83 \\
Specificity (\%) & 70 & 78 & 100 \\
PPV (\%) & 65 & 68 & 100 \\
NPV (\%) & 100 & 91 & 96 \\
Accuracy (\%) & 81 & 81 & 64 \\
\hline
\end{tabular}

FNAC, fine needle aspiration cytology; NPV, negative predictive value; PPV, positive predictive value; $99 \mathrm{mTC}-\mathrm{MIBI}$, technetium-99m methoxyisobutylisonitrile; USG, ultrasonography.

cytology preoperatively. Of these, PCs were positive for malignancy in 4 of 7 nodules (57\%) and only 1 of 8 nodules $(12.5 \%)$ of FCs. In addition, the accuracy of FNAC was lower when compared with the two modalities (64\% for USG vs. $81 \%$ each for $99 \mathrm{mTc}-\mathrm{MIBI}$ and USG).

The diagnostic performance of 99mTc-MIBI scintigraphy, USG and FNAC in assessment of thyroid nodules are presented in Table 2.

\section{Ethical consideration}

The Research Ethics Committees of the University of Limpopo and Dr George Mukhari Academic Hospital approved the study, with ethical clearance number: MREC/M/20/2013: PG. Informed consent was obtained from all of the participants, and confidentiality was observed throughout the study by the use of a number coding system.

\section{Discussion}

A thyroid nodule is one of the frequently encountered problems in endocrinology. The main aim of management is to identify the small proportion of patients with malignant lesions who require prompt intervention and also to avoid unnecessary investigation or treatment for otherwise benign disease. The surgical procedure varies depending on the clinical suspicion for malignancy. Most thyroid nodules can be diagnosed on FNAC, and only follicular neoplasms cannot be reliably identified. ${ }^{5}$ FNAC was diagnostic in only 1 of 8 $(12.5 \%)$ patients with FC. This is of a particular concern in the semi-urban and rural population (like our region) where FC is reported as the predominant primary thyroid cancer. 
Our data revealed an insignificant difference in frequency of the two main types of differentiated thyroid cancers (FC: $53.3 \%$ vs. PC: $46.7 \%$ ). This trend may be a reflection of changing iodine status as a result of widespread iodisation programme. Further, epidemiologic studies are essential to validate this finding. When results are inconclusive or clinical and FNAC findings are discordant, additional diagnostic steps are often crucial to decide on the appropriate surgical actions; such measures include USG, radionuclide imaging and clinical risk stratification using age, gender, size of the nodule, growth rate and prior neck irradiation. 99mTc-MIBI scintigraphy and USG have been investigated independently. To the best of our knowledge, there is no published literature that evaluated hypofunctioning thyroid nodule with $99 \mathrm{mTc}-$ MIBI scintigraphy and USG (utilising both grey scale and Doppler features) at the same time.
99mTc-MIBI was introduced in 1989 as a myocardial perfusion imaging agent, ${ }^{6}$ but it was subsequently shown to accumulate in a variety of tumours, including thyroid neoplasms. ${ }^{6,10} 99 \mathrm{mTc}-\mathrm{MIBI}$ is a lipophilic cationic complex with high affinity for mitochondria, and its accumulation in mitochondria-rich neoplastic cells such as malignant neoplasm is driven by mitochondrial negative transmembrane potential. ${ }^{6}$ Accordingly, $99 \mathrm{mTc}-$ MIBI uptake and retention is more common in neoplastic nodules (carcinomas and adenomas) than it is in other benign conditions. Retention of $99 \mathrm{mTc}-\mathrm{MIBI}$ in thyroid adenomas particularly Hürthle cell is related to high level of mitochondria-rich eosinophilic cells. ${ }^{15}$ Which is why unlike other adenomas, Hürthle cell adenoma shows persistent tracer retention, making it a close rival of malignancy (Figure 1). Nevertheless, despite accumulation

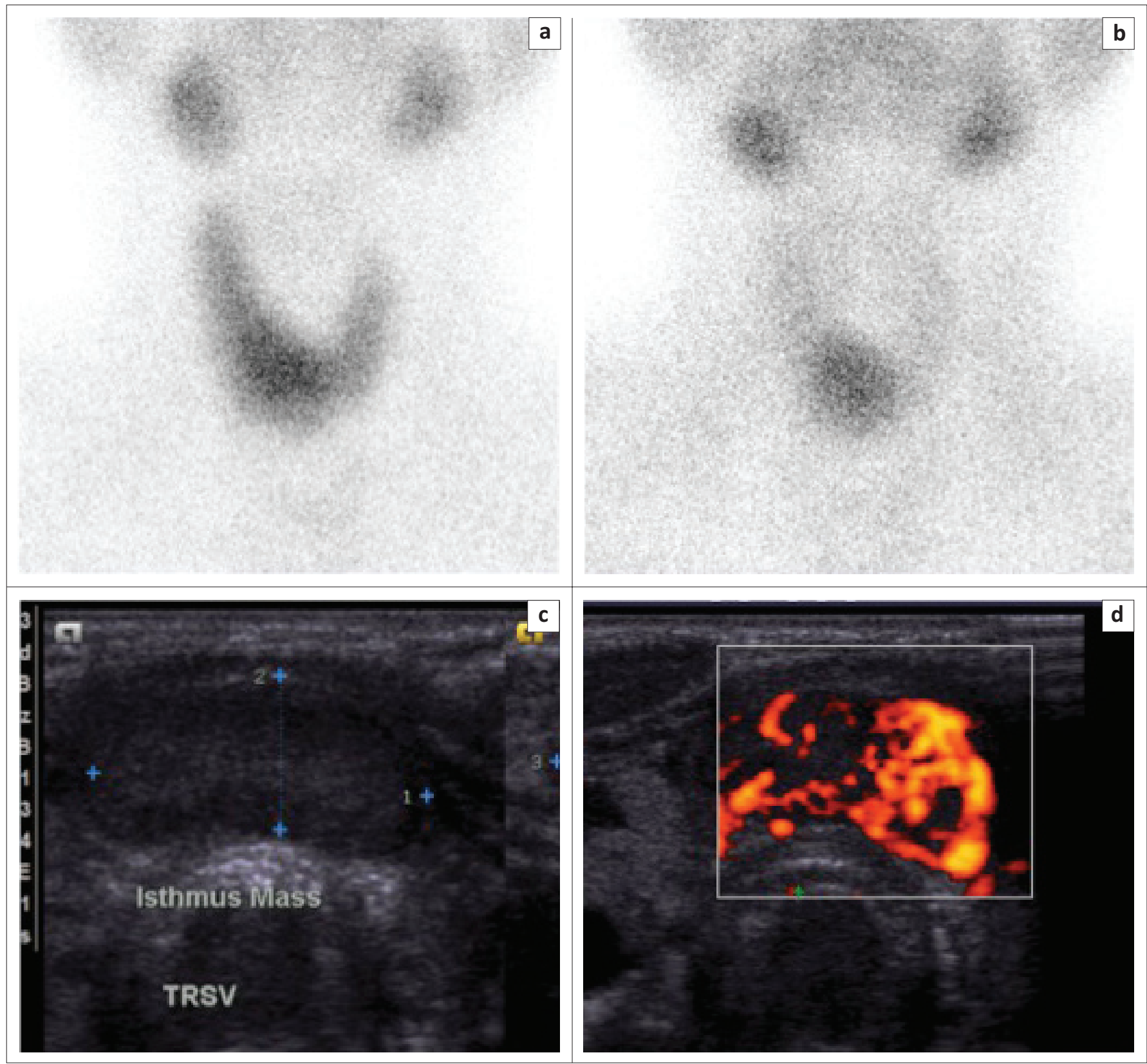

FIGURE 1: $99 \mathrm{mTC}-\mathrm{MIBI}$ scintigraphy and ultrasonography of the thyroid of a 36-year-old woman with isthmic thyroid nodule. There is increased activity on early (a) and delayed (b) $99 \mathrm{mTc}-\mathrm{MIBI}$ scan. Ultrasonography showed a well-defined nodule (c) with marked intranodular vascularity pattern on power Doppler (d). Histology confirmed an Hürthle cell adenoma. 
in adenomas, intense 99mTc-MIBI uptake and retention considerably increases the probability of carcinoma, whereas low or no uptake almost reliably excludes malignancy. ${ }^{6,10}$ For instance, in our study, we found hypofunctioning thyroid nodules that showed malignant characteristics on both 99mTc-MIBI scan and USG; the diagnoses of carcinomas were subsequently confirmed at histology (Figures 2 and 3). Surgical removal of nodules with high 99mTc-MIBI uptake and non-surgical treatment for MIBI-negative nodules had been suggested. ${ }^{16}$

Our study revealed that all the 99mTc-MIBI-positive nodules were confirmed to be malignant and 99mTc-MIBI-negative nodules were proven to be benign at histology. Thus, we obtained sensitivity and NPV of $100 \%$ with 99mTc-MIBI. These findings are consistent with other studies in which they found both the sensitivity and NPV of $100 \% .6,7,8,9$ The high NPV of $99 \mathrm{mTc}-\mathrm{MIBI}$ entails that a negative scan virtually excludes malignancy in a thyroid nodule and this could obviate the need for unnecessary surgical procedures. The major limitation of $99 \mathrm{mTc}-\mathrm{MIBI}$ is the reported wide range of specificity and PPV. $., 7,8,9,10$ We obtained a specificity of $70 \%$ and a PPV of $65 \%$ in our study. These findings correlate closely with studies of Sathekge et al. ${ }^{10}$ (specificity of $66 \%$ and PPV of $77 \%$ ) and Hurtado-López et al. ${ }^{7}$ (specificity of $61 \%$ and PPV of $62 \%$ ). The reported wide range of specificity and PPV may be explained by the uptake of $99 \mathrm{mTc}-\mathrm{MIBI}$ in some
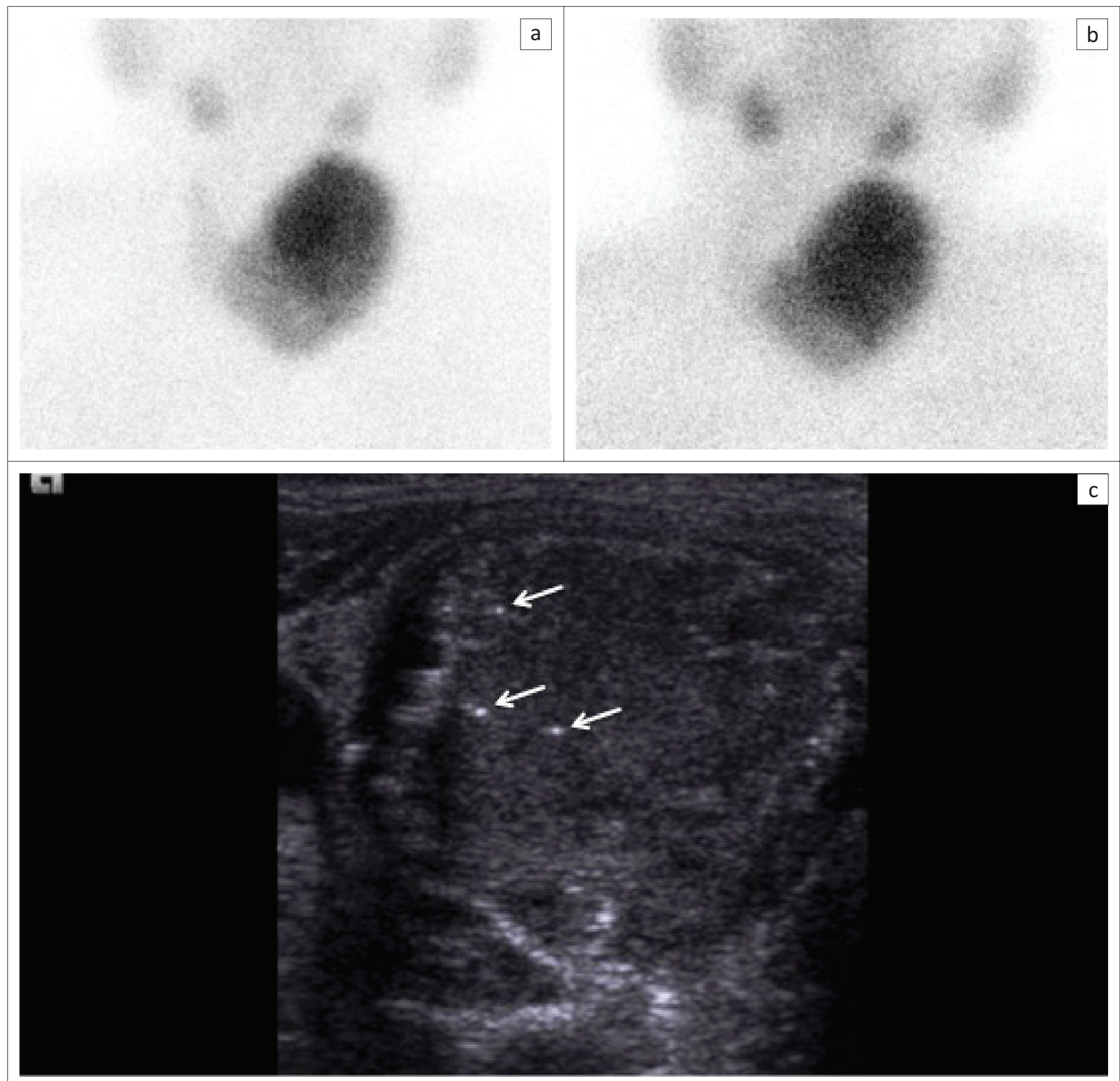

FIGURE 2: 99mTC-MIBI scintigraphy and ultrasonography of the thyroid of a 65 -year-old woman with left thyroid nodule. There is intense $99 \mathrm{mTC}$-MIBI uptake on both early (a) and delayed (b) images in the left lobe of the thyroid. Ultrasonography (c) showed multiple microcalcifications (arrows). The features on the two studies are suggestive of malignancy. Histology confirmed a papillary carcinoma. 

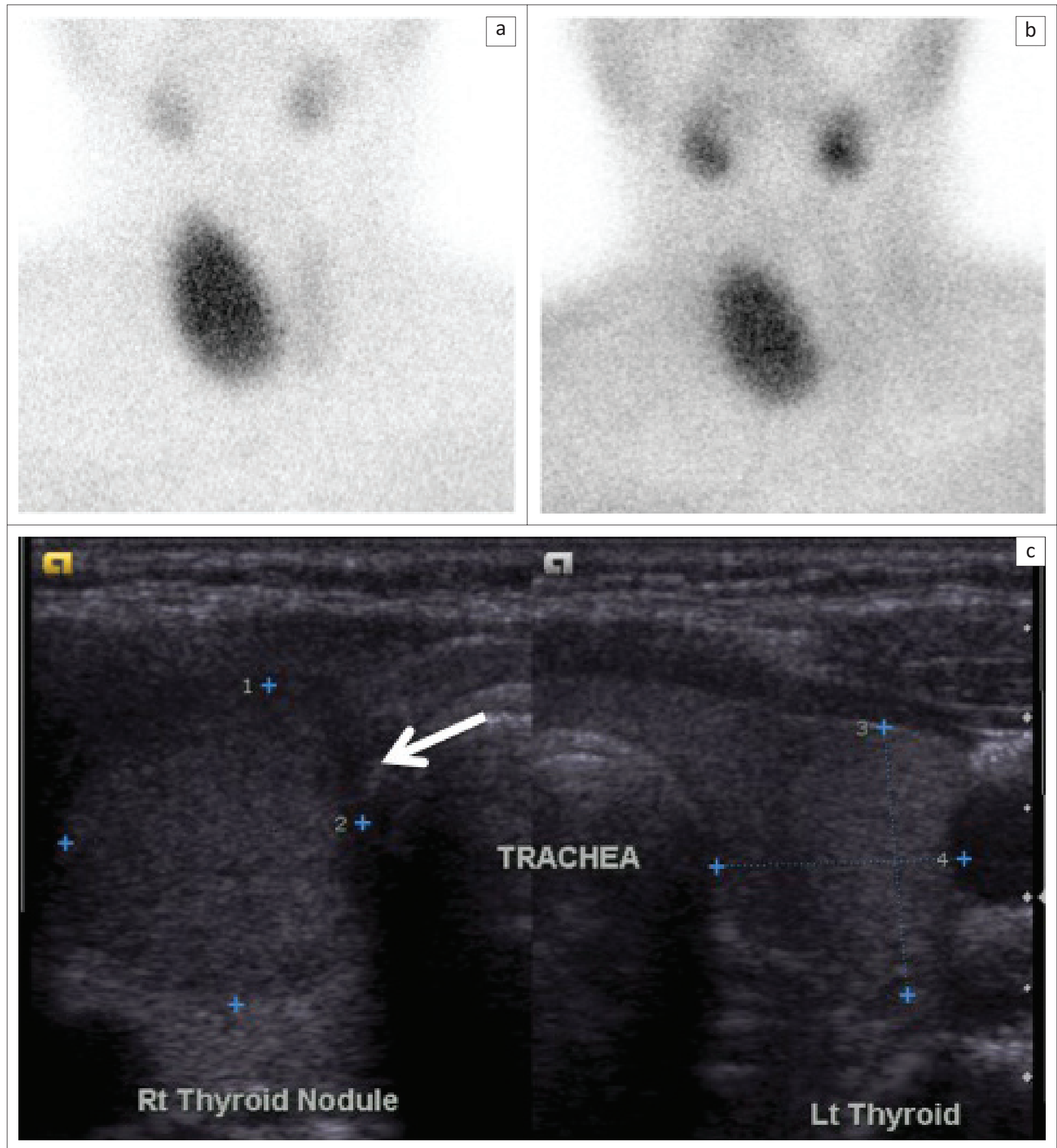

FIGURE 3: 99mTc-MIBI scintigraphy and ultrasonography of the thyroid of a 42-year-old woman with right thyroid nodule. Intense $99 \mathrm{mTc}$-MIBI uptake on early (a) and delayed (b) images is noted in the right lobe of the thyroid. Ultrasonography (c) showed a well-defined mass that is taller than wider shape (arrowed). The features on the two studies are suggestive of malignancy. Histology confirmed a follicular carcinoma.

benign conditions. In our study, all the four thyroid adenomas showed persistent uptake and retention of $99 \mathrm{mTc}-\mathrm{MIBI}$. These findings are similar to the reports of other studies. ${ }^{6,9}$

For the purpose of this study, we focused on evaluating patients with palpable single thyroid nodule regardless of whether or not an additional nodule was present at USG. If we had excluded patients with additional nodule(s), a significant number of patients with thyroid cancers would have been missed. USG revealed additional nodules in 38\% of our cohorts and $25 \%$ of these had malignant nodules. The presence of additional nodule(s) at ultrasound is frequently reported at $20 \%$ to $48 \% .^{2}$ Kaur et al. ${ }^{17}$ found additional nodules in $32 \%$ of their subjects who had single thyroid nodule by palpation. Discrepancy between the true prevalence of thyroid nodules and that obtained by palpation 
has been reported. ${ }^{2}$ The sensitivity, specificity and NPV of USG in the differential diagnosis of nodular thyroid disease in our study were $86.7 \%, 77.8 \%$, and $91.3 \%$, respectively. These are in keeping with the studies of Kaur et al. ${ }^{17}$ and Koike et al. ${ }^{18}$

Furthermore, $99 \mathrm{mTc}-\mathrm{MIBI}$ was more sensitive (100\% vs. $87 \%)$ and had higher NPV (100\% vs. $91 \%)$ compared to USG. Both modalities maintained the same accuracy of $91 \%$. However, they did not differ significantly in terms of their overall performance for both benign $(p=0.317)$ and malignant $(p=0.573)$ nodules. Erdem et al. ${ }^{14}$ compared $99 \mathrm{mTc}-$ tetrofosmin scintigraphy with colour Doppler USG. They found $99 \mathrm{mTc}$-tetrafosmin to be more sensitive than Doppler USG (sensitivity of $100 \%$ vs. $80 \%$ ). However, their study used another ligand (i.e. tetrofosmin) tagged to $99 \mathrm{mTc}$ whose physical properties and mechanism of tumour localisation are similar to MIBI. Demirel et al. ${ }^{9}$ also compared radionuclide thyroid angiography, 99mTc-MIBI with power Doppler USG and found that power Doppler USG was more sensitive than $99 \mathrm{mTc}-\mathrm{MIBI}$ scan (sensitivity of $100 \%$ vs. $67 \%$ ). However, these studies assessed only the Doppler ultrasound features of the nodules and compared them with scintigraphic findings using histology as gold standard (i.e. they did not include other grey scale sonographic characteristics that are suggestive of either benign or malignant nodule as variables).

\section{Limitations of the study}

The relatively small patient cohort is a limitation of our study. Secondly, surgeons might have used all the available information (including results of $99 \mathrm{mTc}-\mathrm{MIBI}$ scintigraphy and ultrasound scan) for surgical decision-making such that only nodules with high suspicion for malignancy were given preference. Consequently, the vast majority of patients with benign nodules would have been left out, potentially introducing a performance bias.

\section{Conclusion}

99mTc-MIBI and USG detected almost all malignant nodules including those nodules that were inconclusive on FNAC. Thus, the two modalities can complement FNAC to improve diagnostic accuracy. This is especially important in follicular neoplasms, which are frequently associated with non-diagnostic cytology (cytology detected merely $12.5 \%$ of FC in our review). $99 \mathrm{mTc}-\mathrm{MIBI}$ and USG can also be used to pre-select patients for FNAC on the basis of suspicious malignant features and the two modalities can help guide biopsy to the most abnormal area.

\section{Acknowledgements}

The authors wish to acknowledge the support of Prof. M.E. Kisansa, the head of Radiology, Sefako Makgatho Health Sciences University and Dr George Mukhari Academic Hospital.

\section{Competing interests}

The authors declare that they have no financial or personal relationships that may have inappropriately influenced them in writing this manuscript.

\section{Authors' contributions}

A.F. was the principal investigator and was responsible for study conception, design, data analysis and manuscript writing. A.A.G. made conceptual contribution, design and manuscript editing. K.D. helped with data collection and performed ultrasound scan. T.M. helped with manuscript editing.

\section{References}

1. Dean DS, Gharib H. Epidemiology of thyroid nodules. Best Pract Res Clin Endocrinol Metab. 2008;22(6):901-911. http://dx.doi.org/10.1016/j.beem.2008.09.019

2. Polyzos SA, Kita M, Avramidis A. Thyroid nodules-Stepwise diagnosis and management. Hormones (Athens). 2007;6(2):101-119. http://dx.doi.org/ 10.14310/horm.2002.111107

3. Kalk WJ, Sitas F, Patterson AC. Thyroid cancer in South Africa: An indicator of regional iodine deficiency. S Afr Med J. 1997;87(6):735-738.

4. McHenry CR, Phitayakorn R. Follicular adenoma and carcinoma of the thyroid gland. Oncologist.2011;16(5):585-593. http://dx.doi.org/10.1634/theoncologist.2010-0405

5. Casara D, Rubello D, Saladini G. Role of scintigraphy with tumor-seeking agents in the diagnosis and preoperative staging of malignant thyroid nodules. Biomed Pharmacother. 2000;54(6):334-336. http://dx.doi.org/10.1016/S0753-3322(00) 80059-1

6. Mezosi E, Bajnok L, Gyory F, et al. The role of technetium-99m methoxyisobutylisonitrile scintigraphy in the differential diagnosis of cold thyroid nodules. Eur I Nucl Med. 1999;26(8):798-803. http://dx.doi.org/10.1007/ s002590050451

7. Hurtado-López LM, Arellano-Montano S, Torres-Acosta EM, et al. Combined use of fine-needle aspiration biopsy, MIBI scans and frozen section biopsy offers the best diagnostic accuracy in the assessment of the hypofunctioning solitary thyroid nodule. Eur J Nucl Med Mol Imaging. 2004;31(9):1273-1279. http://dx.doi. org/10.1007/s00259-004-1544-7

8. Wale A, Miles KA, Young B, et al. Combined $(99 \mathrm{~m})$ Tc-methoxyisobutylisonitrile scintigraphy and fine-needle aspiration cytology offers an accurate and potentially cost-effective investigative strategy for the assessment of solitary or dominant thyroid nodules. Eur J Nucl Med Mol Imaging. 2014;41(1):105-115. http://dx.doi. org/10.1007/s00259-013-2546-0

9. Demirel K, Kapucu O, Yucel C, Ozdemir H, Ayvaz G, Taneri F. A comparison of radionuclide thyroid angiography, $99 \mathrm{mTC}-\mathrm{MIBI}$ scintigraphy and power Doppler
ultrasonography in the differential diagnosis of solitary cold thyroid nodules. Eur J Nucl Med Mol Imaging. 2003;30(5):642-650. http://dx.doi.org/10.1007/ s00259-003-1124-2

10. Sathekge MM, Mageza RB, Muthupei MN, Modiba MC, Clauss RC. Evaluation of thyroid nodules with technetium-99m MIBI and technetium-99m pertechnetate. Head Neck. 2001;23(4):305-310. http://dx.doi.org/10.1002/hed.1035

11. Hoang JK, Lee WK, Lee M, Johnson D, Farrell S. US features of thyroid malignancy Pearls and pitfalls. RadioGraphics. 2007;27(3):847-865. http://dx.doi. org/10.1148/rg.273065038

12. Smith-Bindman R, Lebda $P$, Feldstein VA, et al. Risk of thyroid cancer based on thyroid ultrasound imaging characteristics: Results of a population-bases study. AMA Intern Med. 2013;173(19):1788-1796. http://dx.doi.org/10.1001/ jamainternmed.2013.9245

13. Cappelli C, Pirola I, Gandossi E, et al. Real-time elastography a useful tool for predicting malignancy in thyroid nodules with nondiagnostic cytologic findings. J Ultrasound Med. 2012;31(11):1777-1782.

14. Erdem S, Bashekim C, Kizilkaya E, Ince M, Karsli F. Clinical application of Tc-99m Tetrofosmin scintigraphy in patients with cold thyroid nodules. Comparison with color Doppler sonography. Clin Nucl Med. 1997;22(2):76-79. http://dx.doi. org/10.1097/00003072-199702000-00002

15. Gonzalez-Campora R, Herroro-Zapatero A, Lerma E, Sanchez F, Galera H. Hurthle cell and mitochondrion rich cell tumors: A clinicopathologic study. Cancer 1986;57:1154. http://dx.doi.org/10.1002/1097-0142(19860315)57:6<1154::AIDCNCR2820570616>3.0.CO;2-W

16. Leidig-Bruckner G, Cichorowski G, Sattler P, Bruckner T, Sattler B. Evaluation of thyroid nodules-combined use of $(99 \mathrm{~m})$ Tc-methoxyisobutylisonitrile scintigraphy and aspiration cytology to assess risk of malignancy and stratify patients for surgical or nonsurgical therapy - A retrospective cohort study. Clin Endocrinol (Oxf). 2012;76(5):749-758. http://dx.doi.org/10.1111/j.1365-2265.2011.04292.x

17. Kaur K, Sonkhya N, Bapna AS, Mital P. A comparative study of fine needle aspiration cytology, ultrasonography and radionuclide scan in the management of solitary thyroid nodule: A prospective analysis of fifty cases. Ind J Otolaryngo Head Neck Surg. 2002;54(2):96-101. http://dx.doi.org/10.1007\%2FBF02968725

18. Koike E, Noguchi S, Yamashita $H$, et al. Ultrasonographic characteristics of thyroid nodules: Prediction of malignancy. Arch Surg. 2001;136(3):334-337. http:// dx.doi.org/10.1001/archsurg.136.3.334 